\title{
Rhamnolipids inhibit aflatoxins production in Aspergillus flavus by causing structural damages in the fungal hyphae and down-regulating the expression of their biosynthetic genes
}

\author{
Ana I. Rodrigues ${ }^{a}$, Eduardo J. Gudiña ${ }^{a,{ }^{*}}$, Luís Abrunhosa ${ }^{\mathrm{a}}$, Ana R. Malheiro ${ }^{\mathrm{b}}$, Rui Fernandes ${ }^{\mathrm{b}}$, \\ José A. Teixeira ${ }^{a}$, Lígia R. Rodrigues ${ }^{a}$
}

${ }^{a}$ CEB - Centre of Biological Engineering, University of Minho, 4710-057 Braga, Portugal

${ }^{\mathrm{b}}$ Instituto de Investigação e Inovação em Saúde (I3S), Universidade do Porto, 4200-135 Porto, Portugal

\section{A R T I C L E I N F O}

\section{Keywords:}

Biological control

Biopesticide

Biosurfactant

Fungicide

Mycotoxin

Sporulation

\begin{abstract}
A B S T R A C T
Aflatoxins are hepatotoxic and carcinogenic fungal secondary metabolites that usually contaminate crops and represent a serious health hazard for humans and animals worldwide. In this work, the effect of rhamnolipids (RLs) produced by Pseudomonas aeruginosa \#112 on the growth and aflatoxins production by Aspergillus flavus MUM 17.14 was studied in vitro. At concentrations between 45 and $1500 \mathrm{mg} / \mathrm{L}$, RLs reduced the mycelial growth of $A$. flavus by $23-40 \%$ and the production of aflatoxins by $93.9-99.5 \%$. Purified mono-RLs and di-RLs exhibited a similar inhibitory activity on fungal growth. However, the RL mixture had a stronger inhibitory effect on aflatoxins production at concentrations up to $190 \mathrm{mg} / \mathrm{L}$, probably due to a synergistic effect resulting from the combination of both congeners. Using transmission electron microscopy, it was demonstrated that RLs damaged the cell wall and the cytoplasmic membrane of the fungus, leading to the loss of intracellular content. This disruptive phenomenon explains the growth inhibition observed. Furthermore, RLs down-regulated the expression of genes aflC, aflE, aflP and aflQ involved in the aflatoxins biosynthetic pathway (6.4, 44.3, 38.1 and 2.0-fold, respectively), which is in agreement with the almost complete inhibition of aflatoxins production. Overall, the results herein gathered demonstrate for the first time that RLs could be used against aflatoxigenic fungi to attenuate the production of aflatoxins, and unraveled some of their mechanisms of action.
\end{abstract}

\section{Introduction}

The contamination of foodstuffs and agricultural commodities by mycotoxin-producing fungi is a severe problem that causes substantial economic and health impacts due to losses in crop yield and quality, and their toxicity to humans and animals (Ren et al., 2020). Mycotoxins are a heterogeneous group of extremely toxic secondary metabolites synthesized by certain filamentous fungi that exhibit carcinogenic, mutagenic, immunosuppressive and teratogenic activities. Species belonging to the genera Aspergillus, Penicillium and Fusarium are among the most frequently reported agents of food and feed contamination, and also the primary source of mycotoxins in a wide variety of agricultural products (Lee and Ryu, 2017). The primary cause of human exposure to mycotoxins is the consumption of contaminated crops or foods prepared from them. For instance, it is estimated that approximately $25 \%$ of the cereals produced worldwide are contaminated with mycotoxins (Liew and
Mohd-Redzwan, 2018). Consequently, maximum acceptable concentrations for specific mycotoxins in food and feed are usually established, although the permissible threshold levels vary widely for different crops in different countries (Lee and Ryu, 2017).

Aflatoxins are one of the most relevant groups of mycotoxins, being Aspergillus flavus and Aspergillus parasiticus the main producers (Zhao et al., 2020). Among other relevant crops, rice and corn, which represent a significant fraction of the staple food diet in several countries, are usually contaminated with aflatoxins. In developing countries, outbreaks of acute intoxications (which can lead to death), due to a short exposure to a high concentration of aflatoxins have been reported (Wild and Gong, 2010). In developed countries, the most common is chronic toxicity, due to the continuous consumption of food and feed containing low concentrations of aflatoxins, which results in immunosuppression and the development of different types of cancer (Marchese et al., 2018). Aflatoxin $\mathrm{B}_{1}\left(\mathrm{AFB}_{1}\right)$ is considered the most toxic aflatoxin and the most

\footnotetext{
* Corresponding author at: CEB - Centre of Biological Engineering, University of Minho, Campus de Gualtar, $4710-057$ Braga, Portugal.

E-mail address: egudina@deb.uminho.pt (E.J. Gudiña).
} 
potent carcinogen found in nature, being classified as a Group 1 carcinogen by the International Agency for Research on Cancer. Although the liver is the main target of $\mathrm{AFB}_{1}$, it has also been associated to the development of lung, colon, breast, esophageal and gastric cancer (Marchese et al., 2018; Ren et al., 2020; Wu et al., 2017).

The levels of aflatoxins in food and feed commodities should be reduced to the lowest technologically possible. Accordingly, several strategies (including chemical, physical and biological methods) have been investigated to reduce fungal and aflatoxins contamination in crops. However, such methods are usually limited by their partial efficiency, impairment of some food quality parameters or for leaving toxic residues in the products (Hernández-Falcón et al., 2018; Zhao et al., 2020). Furthermore, due to the difficulty of removing aflatoxins from contaminated products, the prevention of their biosynthesis remains the best solution to avoid food contamination. The use of synthetic fungicides may be a useful strategy to control fungal contamination at preand post-harvest stages in crops. However, these compounds can be detrimental to human and environmental health, and their indiscriminate use can promote the development of resistant fungal strains (Moon et al., 2018; Ren et al., 2020; Sha et al., 2012; Tleuova et al., 2020; Zhao et al., 2020). In that sense, biological control appears to be the most promising approach to manage aflatoxins contamination in crops. The applicability of antagonistic microbial strains for this purpose has been widely demonstrated in the last years, and it is based in four main activities: exclusion of fungal pathogens due to competition for nutrients and space; production of metabolites that inhibit the growth of pathogens; production of metabolites that inhibit the production of aflatoxins; and degradation of produced aflatoxins (Veras et al., 2016). As recently reviewed by Ren et al. (2020), around 50 different microbial species (including bacteria, yeasts and filamentous fungi) have been reported as biocontrol agents against aflatoxigenic fungi. Among the most studied are Bacillus and Lactobacillus spp., which produce a wide variety of inhibitory compounds (e.g. antibiotics, biosurfactants, bacteriocins, organic acids and enzymes) and are usually recognized as safe microorganisms. Due to their ability to reduce the fungal growth and the production of aflatoxins, lipopeptide biosurfactants produced by Bacillus spp. have been widely studied for application as biopesticides for plant and post-harvest protection. These compounds are easily biodegradable in soils, being a healthier and environmentally-friendly alternative to synthetic fungicides, as they display a good balance between efficacy and preservation of the environment (Crouzet et al., 2021; González Pereyra et al., 2018; Veras et al., 2016). Furthermore, lipopeptide biosurfactants can also stimulate the plant immune system, improving plant protection against fungal pathogens (Crouzet et al., 2021), and they are already included in the formulation of fungicides (e.g. Serenade ASO, commercialized by Bayer Crop Science).

Rhamnolipids (RLs) are a class of glycolipid biosurfactants produced mainly by strains of Pseudomonas aeruginosa. RLs comprise a hydrophilic moiety, consisting of one (mono-RLs) or two (di-RLs) rhamnose molecules, linked to a hydrophobic chain, consisting of one or two $\beta$-hydroxy fatty acids. Different RL congeners can be found, depending on the length of the fatty acid units (8-16 carbon atoms) and their degree of saturation (Fig. 1). RLs are usually produced as mixtures of different congeners, and to date more than 60 different RLs have been identified. Besides their excellent surface-active properties, RLs have been reported to exhibit interesting biological activities, including antifungal activity (Borah et al., 2015; Robineau et al., 2020; Rodrigues et al., 2017). However, their effect on the production of aflatoxins has not been reported yet.

The aim of this work was to study the effect of RLs on the growth and aflatoxins production in A. flavus MUM 17.14. For that purpose, the RL mixture produced by $P$. aeruginosa \#112, as well as the purified mono$\mathrm{RL}$ and di-RL congeners were evaluated. In order to study the possible mechanisms involved in growth and aflatoxins production inhibition, the ultrastructural damages caused by RLs on A. flavus MUM 17.14 were studied through transmission electron microscopy (TEM). Finally, the effect of RLs in the expression of some genes involved in fungal sporulation and aflatoxins production was also assessed.

\section{Material and methods}

\subsection{Fungal strain}

A. flavus MUM 17.14, which produced $\mathrm{AFB}_{1}$, was obtained from the culture collection of Micoteca da Universidade do Minho (MUM), Portugal. It was maintained at $-80{ }^{\circ} \mathrm{C}$ in sterile demineralized water supplemented with glycerol $(20 \%, v / v)$. Whenever required, frozen stocks were streaked on Malt Extract Agar (MEA, Blakeslee's formula) plates and incubated at $25{ }^{\circ} \mathrm{C}$ for 7 days. The agar plates were stored at $4{ }^{\circ} \mathrm{C}$ no longer than 3 weeks. The composition of MEA medium was ( $\mathrm{g}$ / L): malt extract, 20; glucose, 20; peptone, 1; agar, 20; $\mathrm{pH}$ 5.5.

\subsection{Rhamnolipids}

The RLs used in this study were purified and characterized in our previous works (Gudiña et al., 2016; Rodrigues et al., 2017). Briefly, the RL mixture produced by $P$. aeruginosa \#112 was purified through liquid column chromatography using the polystyrene resin Amberlite XAD-2 (Sigma-Aldrich Co., USA). The purity of the RL mixture, estimated through HPLC (Hruzová et al., 2020) and using 90\% pure RLs (R90,<smiles>CC1CCC(OC(=O)CC2CCCCC2)C(OC2OC(C)C(O)C(O)C2O)C1</smiles>

mono-rhamnolipids

(Rha- $\mathrm{C}_{\mathrm{m}}-\mathrm{C}_{\mathrm{n}}$ )<smiles>CC1OC(OC2C(OC3C(CC(=O)OC(CC(=O)O)C4CCCC4)CCC3(C)C)OC(C)C(O)C2O)C(O)C(O)C1O</smiles>

\section{di-rhamnolipids \\ (Rha-Rha- $C_{m}-C_{n}$ )}

Fig. 1. Structure of mono- and di-rhamnolipids. $\mathrm{n}, \mathrm{m}=4,6,8,10$ or 12 . 
Sigma-Aldrich Co., USA) as reference was $92 \%$. The purified RL mixture contained mono-RLs (Rha- $\mathrm{C}_{10}-\mathrm{C}_{10} 41 \%$; Rha- $\mathrm{C}_{10} 16 \%$; Rha- $\mathrm{C}_{10}-\mathrm{C}_{12} 5 \%$ ) and di-RLs (Rha-Rha- $\mathrm{C}_{10}-\mathrm{C}_{10} 25 \%$; Rha-Rha- $\mathrm{C}_{10}-\mathrm{C}_{12} 6 \%$; Rha-Rha- $\mathrm{C}_{10}$ $5 \%$; Rha-Rha- $\mathrm{C}_{10}-\mathrm{C}_{8} 2 \%$ ) (Gudiña et al., 2016). The mono- and di-RL congeners present in the RL mixture were subsequently separated through silica gel column chromatography (Gudiña et al., 2016; Rodrigues et al., 2017).

\subsection{Effect of RLs on fungal growth and aflatoxins production}

The antifungal activity of the RLs produced by $P$. aeruginosa \#112 against A. flavus MUM 17.14 was evaluated in Petri dishes $(55 \mathrm{~mm}$ diameter) containing MEA medium supplemented with the freeze-dried RLs (RL mixture and purified mono- and di-RL congeners) at different concentrations (45-1500 mg/L). The agar plates were inoculated with $10 \mu \mathrm{L}$ of a spore suspension of $A$. flavus MUM 17.14 (prepared in sterile demineralized water with a concentration of $1 \times 10^{5}$ spores $/ \mathrm{mL}$, according to Rodrigues et al. (2017)) in the center of the plate. Subsequently, the plates were incubated at $25{ }^{\circ} \mathrm{C}$ for 5 days. Control assays were performed using MEA medium without RLs. The fungal radial growth was determined by measuring the diameter of the growth zone. The percentage of radial growth inhibition relative to the control was calculated as follows:

Growth inhibition $x(\%)=\left(1-\frac{\text { diameter } x}{\text { diameter } c}\right) \times 100$

where diameter $x(\mathrm{~cm})$ represents the diameter of the mycelial growth in the medium with the treatment $x$, and diameter $c$ represents the diameter of the fungal growth in the control. All the experiments were performed in triplicate.

The effect of RLs on the production of aflatoxins by A. flavus MUM 17.14 was studied using the same plates at the end of the incubation period (5 days). The entire content of each plate was cut into pieces, transferred to a $50 \mathrm{~mL}$ tube and extracted with $20 \mathrm{~mL}$ of a mixture containing acetonitrile:methanol:acetic acid $(78: 20: 2, \mathrm{v} / \mathrm{v} / \mathrm{v})$ by agitation with vortex at high speed. The extracts were left overnight at room temperature in the dark. Subsequently, $2 \mathrm{~mL}$ of each extraction were filtered through a $0.2 \mu \mathrm{m}$ syringe filter and analyzed by HPLC with fluorescence detection according to the methodology described by Guimarães et al. (2018). The detection (S/N of 2:1) and quantification limit (S/N of 10:1) of the method were 3.3 and $16.5 \mathrm{ng} / \mathrm{mL}$, respectively. Repeatability was evaluated by calculating a pooled RSD using 24 samples performed in triplicate $\left(\mathrm{RSD}_{\text {pooled }}=19 \%\right)$. Mean recoveries ( 98 $\pm 9 \%$ ) were evaluated by extracting plates containing MEA medium supplemented with $3 \mu \mathrm{g}$ of $\mathrm{AFB}_{1}$ in triplicate. The HPLC system used was equipped with a Varian Prostar 210 pump, a Varian Prostar 410 autosampler, a photochemical post-column derivatization reactor (PHRED unit, Aura Industries, USA) and a Jasco FP-920 fluorescence detector. The instrument and the chromatographic data were managed by a Varian 850-MIB data system interface and a Galaxie chromatography data system, respectively. A $\mathrm{C}_{18}$ reversed-phase YMC-Pack ODS-A analytical column $(250 \times 4.6 \mathrm{~mm}$ i.d., $5 \mu \mathrm{m}$ particle size $)$ connected to a guard column with the same stationary phase was used. The mobile phase used was a mixture of water:acetonitrile:methanol (3:1:1, v/v/v), and the column oven temperature was set to $30^{\circ} \mathrm{C}$. The injection volume was $30 \mu \mathrm{L}$, and the compounds were eluted at a flow rate of $1.0 \mathrm{~mL} / \mathrm{min}$ for a $20 \mathrm{~min}$ isocratic run. The fluorescence of aflatoxins was recorded at excitation and emission wavelengths of 365 and $435 \mathrm{~nm}$, respectively. Calibration curves of aflatoxins were prepared in mobile phase using a certified aflatoxins standard solution mixture (46304-U, Sigma-Aldrich, USA) at a concentration range of $50-1000 \mathrm{ng} / \mathrm{mL}$. Aflatoxins were quantified by comparing the peak areas in the samples with those of the calibration curves. All the analyses were performed in triplicate.

\subsection{Effect of RLs on sporulation}

To analyze the effect of RLs in the production of spores in A. flavus MUM 17.14, an aliquot containing $1 \times 10^{5}$ spores was spread onto $5 \mathrm{~mL}$ of MEA solid medium (containing $1500 \mathrm{mg} \mathrm{RL}$ mixture/L) in $15 \mathrm{~mL}$ tubes. The tubes were incubated in the dark at $25{ }^{\circ} \mathrm{C}$ for 5 days. At the end of the growth period, the spores were harvested by washing them out from the agar surface through the successive addition of $1 \mathrm{~mL}$ of a Tween 20 solution $(0.01 \%, v / \mathrm{v})$ until a final volume of $10 \mathrm{~mL}$. The number of spores in the suspensions was counted using a Neubauer improved cell counter (Marienfeld GmbH, Germany). MEA without RLs was used as control. The assays were performed in triplicate.

\subsection{Isolation of total RNA and gene expression assays}

$100 \mathrm{~mL}$ flasks containing $50 \mathrm{~mL}$ of MEA liquid medium supplemented with $1500 \mathrm{mg}$ RL mixture/L were inoculated with $1 \times 10^{6}$ spores of A. flavus MUM 17.14. MEA medium without RLs was used as control. The cultures were incubated at $28{ }^{\circ} \mathrm{C}$ and $150 \mathrm{rpm}$ for 3 days. Subsequently, the cultures were centrifuged ( $9000 \times g, 20 \mathrm{~min}$ ), the supernatants were removed and the mycelia were collected and immediately frozen at $-80^{\circ} \mathrm{C}$ for total RNA extraction. The supernatants were stored at $-20{ }^{\circ} \mathrm{C}$ and used to evaluate the production of aflatoxins through HPLC, as described above. Four replicates of each condition were performed.

The mycelia recovered from the different assays were ground to a fine powder using a mortar and a pestle under liquid nitrogen. Subsequently, total RNA was extracted using the Plant/Fungi Total RNA Purification Kit (NORGEN Biotek Corporation, Canada), followed by treatment with RNase-free DNase I (Thermo Fisher Scientific Inc., USA) to degrade contaminating genomic DNA, according to the manufacturer's instructions. The concentration and purity of the extracted RNA samples was assessed by measuring the absorbance at $260 / 280 \mathrm{~nm}$ using a NanoDrop ${ }^{\mathrm{TM}}$ One/One ${ }^{\mathrm{C}}$ Microvolume UV-Vis Spectrophotometer (Thermo Fisher Scientific Inc., USA). The integrity of the RNA was evaluated through agarose gel $(0.8 \%, w / v)$ electrophoresis. The purified RNA was stored at $-80^{\circ} \mathrm{C}$ until use. The complementary DNA (cDNA) was synthesized using the Xpert cDNA Synthesis Mastermix (Grisp Lda., Portugal), following the manufacturer's instructions. Real-Time PCR (qPCR) assays were performed in a CFX96 ${ }^{\mathrm{TM}}$ thermal cycler (Bio-Rad, USA). Gene-specific primers synthesized by Metabion International AG (Germany) and Eurofins Genomics (Germany) were used to analyze the expression of some of the genes involved in aflatoxins biosynthesis ( $\mathrm{aflC}$, afle, aflP, aflQ, aflR and aflS) and sporulation (brlA, abaA and wetA) (Table 1). Each reaction contained the optimized concentrations of cDNA and primers, and $5 \mu \mathrm{L}$ of Xpert Fast SYBR (Grisp Lda., Portugal), in a final volume of $10 \mu \mathrm{L}$. Subsequently, they were incubated at $95{ }^{\circ} \mathrm{C}$ for $2 \mathrm{~min}$, followed by 40 cycles of $5 \mathrm{~s}$ at $95^{\circ} \mathrm{C}$ and $20 \mathrm{~s}$ at $60^{\circ} \mathrm{C}$. A melting curve ( 65 to $95^{\circ} \mathrm{C}, 1{ }^{\circ} \mathrm{C} / \mathrm{min}$ ) was generated at the end of the reaction to assess the specificity of the amplification and discard the presence of primer dimers. The $\beta$-tubulin gene was used to normalize the expression of the target genes. Appropriate controls (no template control, no reverse transcriptase control and negative control) were performed. The efficiency $(E)$ of each set of primers was calculated by the Bio-Rad CFX96 Manager Software ${ }^{\mathrm{TM}}$ using a calibration curve obtained using 10-fold serial dilutions of cDNA from the control assays as a template, and the thermal cycling conditions described above. Relative expression levels and fold differences were calculated with the mathematical models proposed by Pfaffl (2001) using the threshold cycle (Ct) values obtained and the corresponding primer efficiencies. Four independent replicates of each condition were analyzed in triplicate.

\subsection{Transmission electron microscopy (TEM) analysis}

Samples of A. flavus MUM 17.14 grown in agar plates (MEA medium and MEA medium containing $1500 \mathrm{mg}$ RL mixture/L) for 5 days were 
Table 1

Primers used to study the expression of genes related to aflatoxins biosynthesis and sporulation through qPCR. $E$ (\%): primers efficiency. $\mathrm{Tm}\left({ }^{\circ} \mathrm{C}\right)$ : primer melting temperature.

\begin{tabular}{|c|c|c|c|c|}
\hline $\begin{array}{l}\text { Target } \\
\text { gene }\end{array}$ & Nucleotide sequence $\left(5^{\prime}-3^{\prime}\right)$ & $\begin{array}{l}E \\
(\%)\end{array}$ & $\begin{array}{l}\mathrm{Tm} \\
\left({ }^{\circ} \mathrm{C}\right)\end{array}$ & Reference \\
\hline aflC & $\begin{array}{l}\text { Fw: TGCATGGCGATGTGGTAGTT } \\
\text { Rv: GTAAGGCCGCGAGAGAAAG }\end{array}$ & 103 & $\begin{array}{l}60.04 \\
58.33\end{array}$ & $\begin{array}{l}\text { Moon } \\
\text { et al. } \\
(2018)\end{array}$ \\
\hline afLE & $\begin{array}{l}\text { Fw: TCTAGCGCCGGTGTTCGT } \\
\text { Rv: TTACCCCTTTCCAGCCATTG }\end{array}$ & 101 & $\begin{array}{l}61.37 \\
57.77\end{array}$ & $\begin{array}{l}\text { Moon } \\
\text { et al. } \\
\text { (2018) }\end{array}$ \\
\hline aflP & $\begin{array}{l}\text { Fw: CGATCTTTTGGCCCAGGAT } \\
\text { Rv: CAACCGTCATGTCGATCTGATT }\end{array}$ & 98 & $\begin{array}{l}63.00 \\
63.60\end{array}$ & $\begin{array}{l}\text { Chang } \\
\text { et al. } \\
\text { (2012a) }\end{array}$ \\
\hline aflQ & $\begin{array}{l}\text { Fw: GTCGCATATGCCCCGGTCGG } \\
\text { Rv: GGCAACCAGTCGGGTTCCGG }\end{array}$ & 101 & $\begin{array}{l}65.72 \\
65.79\end{array}$ & $\begin{array}{l}\text { Wang } \\
\text { et al. } \\
\text { (2017) }\end{array}$ \\
\hline aflR & $\begin{array}{l}\text { Fw: GGGAACAAGAGGGCTACCGA } \\
\text { Rv: TGCCAGCACCTTGAGAACG }\end{array}$ & 103 & $\begin{array}{l}61.26 \\
60.60\end{array}$ & $\begin{array}{l}\text { Kong et al. } \\
\text { (2010) }\end{array}$ \\
\hline afls & $\begin{array}{l}\text { Fw: GGTCGTGCATGTGCGAATC } \\
\text { Rv: GAGGGCAACAACCAGTGAGG }\end{array}$ & 100 & $\begin{array}{l}59.94 \\
60.89\end{array}$ & $\begin{array}{l}\text { Kong et al. } \\
\text { (2010) }\end{array}$ \\
\hline$a b a A$ & $\begin{array}{l}\text { Fw: TCTTCGGTTGATGGATGATTTC } \\
\text { Rv: CCGTTGGGAGGCTGGGT }\end{array}$ & 101 & $\begin{array}{l}56.50 \\
61.36\end{array}$ & $\begin{array}{l}\text { Han et al. } \\
(2016)\end{array}$ \\
\hline brlA & $\begin{array}{l}\text { Fw: } \\
\text { TATCCAGACATTCAAGACGCACAG } \\
\text { Rv: } \\
\text { GATAATAGAGGGCAAGTTCTCCAAAG }\end{array}$ & 97 & $\begin{array}{l}60.92 \\
59.52\end{array}$ & $\begin{array}{l}\text { Chang } \\
\text { et al. } \\
(2012 \mathrm{a})\end{array}$ \\
\hline wetA & $\begin{array}{l}\text { Fw: CCACAGCAGCCGATCCA } \\
\text { Rv: CCCCTTGCAGGATGTCATG }\end{array}$ & 102 & $\begin{array}{l}59.35 \\
58.20\end{array}$ & $\begin{array}{l}\text { Chang } \\
\text { et al. } \\
\text { (2012b) }\end{array}$ \\
\hline$\beta$-tubulin & $\begin{array}{l}\text { Fw: TTGAGCCCTACAACGCCACT } \\
\text { Rv: TGGTTCAGGTCACCGTAAGAGG }\end{array}$ & 101 & $\begin{array}{l}61.76 \\
61.67\end{array}$ & $\begin{array}{l}\text { Wang } \\
\text { et al. } \\
\text { (2017) }\end{array}$ \\
\hline
\end{tabular}

fixed by immersion in $2.5 \%$ glutaraldehyde and $2 \%$ paraformaldehyde (prepared in $0.1 \mathrm{M}$ sodium cacodylate buffer ( $\mathrm{pH}$ 7.4)) solution for 5 days. After washing and $2 \mathrm{~h}$ in post-fixating $2 \%$ osmium tetroxide in 0.1 M sodium cacodylate buffer ( $\mathrm{pH}$ 7.4) solution, the samples were washed in buffer, incubated with $1 \%$ uranyl acetate overnight, washed in buffer, dehydrated through graded series of ethanol, and finally embedded in Epon (EMS). Ultrathin sections were cut at $50 \mathrm{~nm}$ on an RMC Ultramicrotome (PowerTome, USA) using a diamond knife and recovered to 200 mesh Formvar Ni-grids, followed by post staining using $2 \%$ uranyl acetate and saturated lead citrate solution. Visualization was performed at $80 \mathrm{kV}$ in a JEM-1400 microscope (JEOL, Japan) and digital images were acquired using a CCD digital camera Orious $1100 \mathrm{~W}$ (Japan).

\subsection{Statistical analysis}

All data were expressed as the means \pm standard deviation of at least three independent replicates. Results from aflatoxins production and fungal growth were analyzed using one-way analysis of variance (ANOVA) followed by the Tukey's HSD multiple comparisons test. Results from qPCR and sporulation assays were analyzed using the Student's $t$-test. All statistical analyses were performed at a significance level of 0.05 using the software GraphPad Prism 7 for Windows (GraphPad Software, La Jolla California, USA).

\section{Results and discussion}

\subsection{Antifungal activity of RLs against Aspergillus flavus MUM 17.14}

The development of new environmentally-friendly treatments to reduce or eliminate mycotoxins in food is of utmost importance; hence

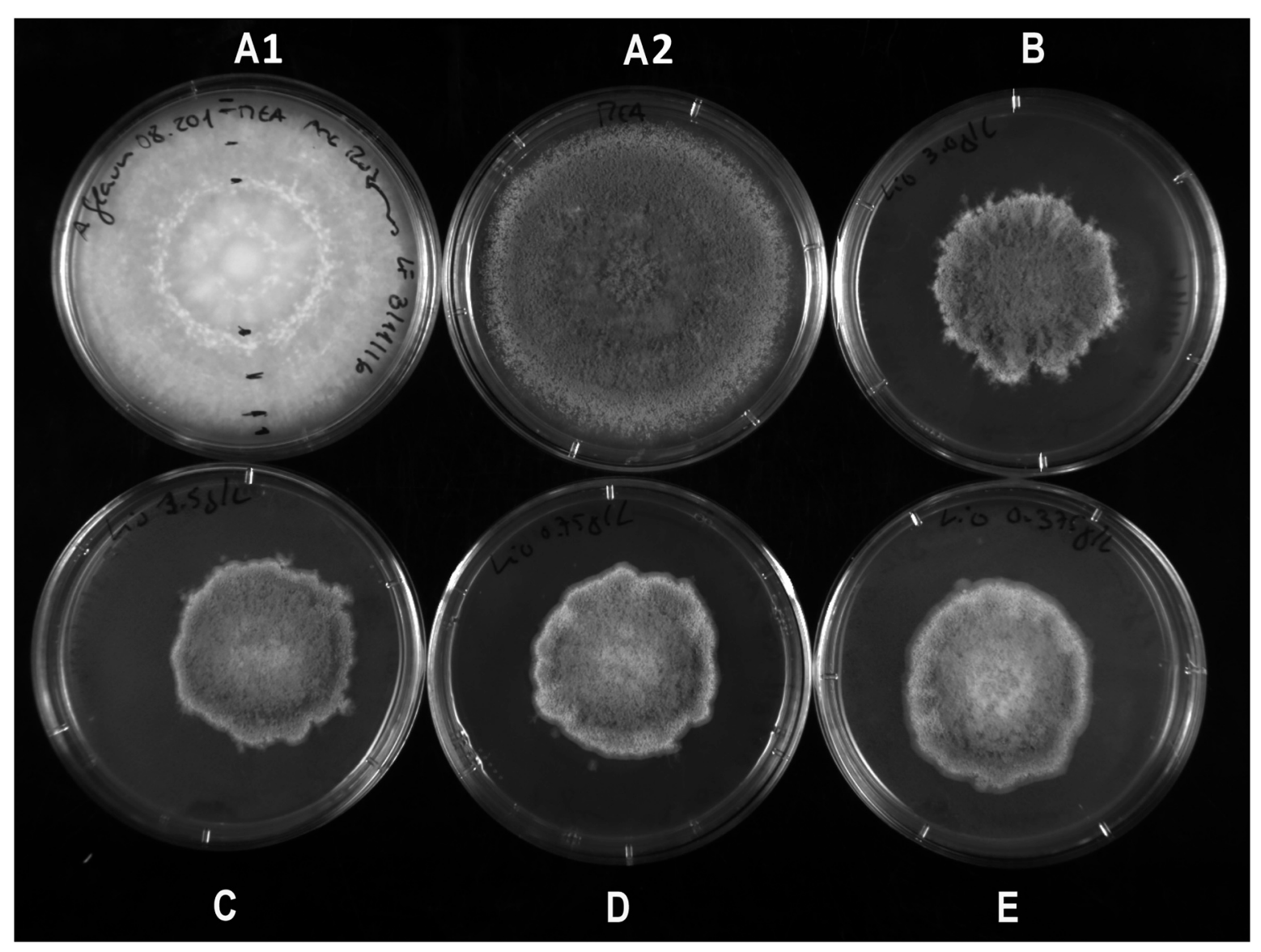

Fig. 2. Antifungal activity of the rhamnolipid (RL) mixture produced by Pseudomonas aeruginosa \#112 at different concentrations against Aspergillus flavus MUM 17.14. A1: $0 \mathrm{mg}_{\mathrm{RL}} / \mathrm{L}$ (reverse view); A2: $0 \mathrm{mg}_{\mathrm{RL}} / \mathrm{L}$ (top view); B: $3000 \mathrm{mg}_{\mathrm{RL}} / \mathrm{L} ; \mathrm{C}: 1500 \mathrm{mg}_{\mathrm{RL}} / \mathrm{L} ; \mathrm{D}: 750 \mathrm{mg}_{\mathrm{RL}} / \mathrm{L} ; \mathrm{E}: 375 \mathrm{mg}_{\mathrm{RL}} / \mathrm{L}$. 
in this work, the effect of RLs on the growth of A. flavus MUM 17.14, as well as on its aflatoxins production, was studied. The antagonistic activity of RLs against A. flavus MUM 17.14 was first evaluated using the RL mixture at different concentrations (Fig. 2). As it can be seen in Table 2, similar growth inhibition percentages (34-40\%) were obtained with the RL mixture at concentrations between 90 and $1500 \mathrm{mg} / \mathrm{L}$. These results agree with previous studies that reported antifungal activity of RLs produced by $P$. aeruginosa and synthetic RL-derivatives against other genera of fungi, including Botrytis, Colletotrichum, Fusarium and Phytophthora, at concentrations between 25 and $450 \mathrm{mg} / \mathrm{L}$ (Borah et al., 2015; Kim et al., 2000; Reddy et al., 2016; Robineau et al., 2020; Sha et al., 2012). Regarding the purified mono- and di-RL congeners, they exhibited a similar inhibitory activity against A. flavus MUM 17.14, although other authors reported different activities for different RL congeners (Borah et al., 2015; Robineau et al., 2020). Only at the lowest and the highest concentrations tested, di-RLs exhibited a statistically significant $(p<0.05)$ higher antagonistic activity comparing to mono-RLs (Table 2).

As it can be seen from Table 2, RLs only partially inhibited the growth of A. flavus MUM 17.14, and a relationship between RLs concentration and growth inhibition was not observed. Similar results were obtained by Rodrigues et al. (2017) regarding the antifungal activity of RLs against Aspergillus niger and Aspergillus carbonarius. In that case, it was demonstrated that the antifungal activity of RLs against those fungi was related to their aggregation behavior, which can be modified by changing the $\mathrm{pH}$ or the ionic strength of the culture medium (Rodrigues et al., 2017).

Contrary to the mycelial growth, the production of spores was significantly increased $(p<0.05)$ by the RL mixture at a concentration of $1500 \mathrm{mg} / \mathrm{L}$ : from $6.57 \times 10^{6} \pm 0.67 \times 10^{6}$ spores $/ \mathrm{mL}$ to $1.82 \times 10^{7} \pm$ $0.18 \times 10^{7}$ spores $/ \mathrm{mL}$. This can be explained as a stress response of A. flavus to the presence of RLs.

The internal structures of hyphae and spores of A. flavus MUM 17.14 grown in the presence of RLs (1500 mg RL mixture/L) were analyzed by TEM. Regarding the spores, TEM images from cultures grown in the presence of RLs (Fig. 3C) showed that they remained intact, electronopaque, and their cell components were well arranged, as for the spores obtained from cultures grown without RLs (Fig. 3A). However, it could be observed a slight deformation on the spore structure compared to the round shape observed in control. In the non-treated hyphae (Fig. 3B), it was possible to observe a uniform shape, as well as an intact cell wall and membrane, a good internal organization and the presence of organelles, including Golgi complex, mitochondria and vacuoles with normal appearance and regular distribution. Contrarily, RLs seriously damaged the hyphal cell structure. In hyphae grown in the presence of RLs, it was possible to observe considerable damages in the cell wall, lysis and disappearance of the cell membrane, loss of mitochondria and other organelles, increased lipid content and lack of intracellular content

Table 2

Growth inhibition percentages obtained for Aspergillus flavus MUM 17.14 with the rhamnolipid mixture and with the purified mono- and di-rhamnolipid congeners at different concentrations. The assays were performed at $25{ }^{\circ} \mathrm{C}$ for 5 days. The results represent the average of three independent experiments \pm standard deviation.

\begin{tabular}{|c|c|c|c|}
\hline \multirow[b]{2}{*}{ [RL] mg/L } & \multicolumn{3}{|c|}{ Growth Inhibition (\%) } \\
\hline & RL mixture & Mono-RL & Di-RL \\
\hline 0 & $0.0 \pm 0.0^{\mathrm{a}}$ & $0.0 \pm 0.0^{\mathrm{a}}$ & $0.0 \pm 0.0^{\mathrm{a}}$ \\
\hline 45 & $23.5 \pm 2.8^{\mathrm{bB}}$ & $27.5 \pm 1.5^{\mathrm{bB}}$ & $37.8 \pm 0.0^{\mathrm{bA}}$ \\
\hline 90 & $38.9 \pm 1.8^{\mathrm{cA}}$ & $36.8 \pm 3.1^{\mathrm{cA}}$ & $40.9 \pm 2.3^{\mathrm{bA}}$ \\
\hline 190 & $40.9 \pm 1.8^{\mathrm{cB}}$ & $43.5 \pm 2.3^{\mathrm{dAB}}$ & $47.2 \pm 1.0^{\mathrm{cA}}$ \\
\hline 375 & $34.7 \pm 2.0^{\mathrm{cB}}$ & $47.2 \pm 1.0^{\mathrm{dA}}$ & $46.1 \pm 2.5^{\mathrm{cA}}$ \\
\hline 750 & $39.5 \pm 6.2^{\mathrm{cA}}$ & $46.6 \pm 0.9^{\mathrm{dA}}$ & $46.1 \pm 2.5^{\mathrm{cA}}$ \\
\hline 1500 & $40.1 \pm 2.4^{\mathrm{cB}}$ & $36.1 \pm 4.5^{\mathrm{cB}}$ & $49.5 \pm 2.7^{\mathrm{cA}}$ \\
\hline
\end{tabular}

Different lower case letters within the same column and different capital letters within the same row indicate statistically significant differences $(p<0.05)$.
(Fig. 3D).

The mechanisms involved in the antifungal activity of RLs are not well established, and it is usually assumed that due to their detergentlike effect they interact with the biological membranes, disturbing their integrity and permeability by inducing the formation of pores and ion channels, which ultimately results in cell lysis (Sánchez et al., 2007). This is in accordance with the damages caused by RLs in the A. flavus hyphae herein observed (Fig. 3B and D), which supports that mechanism of action. The fact that RLs displayed more damages in the hyphae than in the spores can be due to the differences in the thickness of their cell walls.

Lipopeptide biosurfactants produced by Bacillus species have been reported to exhibit strong antifungal activity against aflatoxinproducing A. flavus strains (Afsharmanesh et al., 2014; Gong et al., 2014; Moyne et al., 2001). Among the different lipopeptide families (iturins, fengycins and surfactins), iturin A and bacillomycin D (both of them belonging to the iturin family) demonstrated to be the most effective, although they exhibited lower surface activity when compared with surfactin (Afsharmanesh et al., 2014; Gong et al., 2014). In the case of bacillomycin D, growth inhibition achieved $85 \%$ at a concentration of $200 \mathrm{mg} / \mathrm{L}$ (Gong et al., 2014). Several studies demonstrated that these biosurfactants alter the integrity of the fungal cell wall and the permeability of the cytoplasmic membrane of hyphae and spores of A. flavus (Afsharmanesh et al., 2014; Gong et al., 2014). According to Moyne et al. (2001), ergosterol and cholesterol could be the target of bacillomycin D. Ergosterol was also identified as the target for the antifungal compounds present in the cell-free supernatants of cultures of Bacillus amyloliquefaciens UTB2 and B. subtilis UTB3 (probably lipopeptide biosurfactants), which reduced the growth of the aflatoxigenic fungus Aspergillus parasiticus NRRL 2999 by 90\% (Siahmoshteh et al., 2018). RLs display a lower inhibitory activity against $A$. flavus when compared with lipopeptide biosurfactants, which can be due to their different mechanisms of action resulting from their different structures.

\subsection{Effect of RLs on aflatoxins production by Aspergillus flavus MUM 17.14}

The effect of RLs on the production of aflatoxins by A. flavus MUM 17.14 was studied using the RL mixture and the purified mono- and diRL congeners at different concentrations. Analyzing Table 3 it can be observed that the RL mixture almost completely inhibited $\mathrm{AFB}_{1}$ production (93.9-99.5\%) at all the concentrations tested. On the other hand, although at the highest concentration tested $(1500 \mathrm{mg} / \mathrm{L})$ the mono- and di-RLs inhibited $\mathrm{AFB}_{1}$ production by $98-99 \%$, their inhibitory activity at low concentrations was significantly lower $(p<0.05)$ comparing with the RL mixture. Furthermore, at concentrations between 190 and $1500 \mathrm{mg} / \mathrm{L}$, di-RLs exhibited a statistically significant higher inhibition $(p<0.05)$ than mono-RLs. The high inhibitions observed for the RL mixture at concentrations up to $190 \mathrm{mg} / \mathrm{L}$ when compared with the purified mono- and di-RL congeners can be due to a synergistic effect resulting from their combination. Similar synergistic effects were previously reported for lipopeptide biosurfactants. Surfactin, despite its outstanding surface activity, exhibits a weak antifungal activity against $A$. parasiticus. However, it considerably increases the antifungal activity of other lipopeptide biosurfactants such as iturin A and fengycins (González Pereyra et al., 2018).

Similarly to the results herein obtained, previous works demonstrated an inhibition of aflatoxins production not directly related to the inhibition of fungal growth. Since aflatoxins are secondary metabolites, their production is not necessary for fungal growth. The cell-free supernatants of Lactobacillus plantarum UM55 cultures inhibited the growth of A. flavus MUM 17.14 by $32 \%$, whereas the production of aflatoxins was reduced by $95 \%$. This inhibitory effect was due to the presence of different organic acids that can act as specific inhibitors of aflatoxins production, being phenyllactic acid the most relevant (Guimarães et al., 2018). 


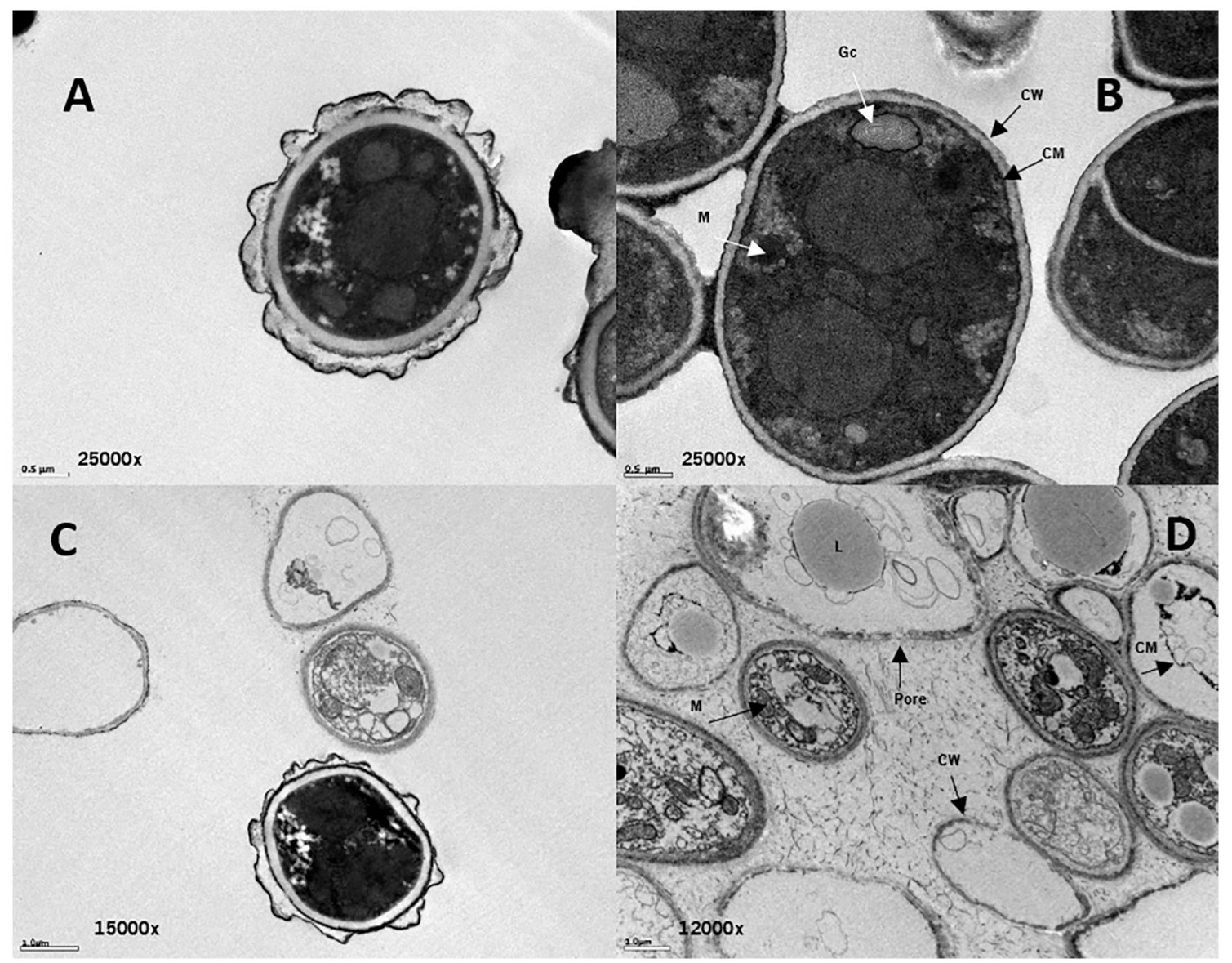

Fig. 3. Transmission electron microscopy sections of spores and hyphae of Aspergillus flavus MUM 17.14 grown in MEA plates for 5 days at $25{ }^{\circ}$ C. A, B: MEA. C, D: MEA supplemented with $1500 \mathrm{mg}$ rhamnolipid mixture/L. CW: cell wall; CM: cell membrane; Gc: Golgi's complex; M: mitochondria; L: lipid content.

Table 3

Aflatoxin $\mathrm{B}_{1}\left(\mathrm{AFB}_{1}\right)$ concentration and percentage of $\mathrm{AFB}_{1}$ reduction (relative to the control) in cultures of Aspergillus flavus MUM 17.14 grown in the presence of the rhamnolipid mixture and the purified mono- and di-rhamnolipids at different concentrations. The results represent the average of three independent experiments \pm standard deviation.

\begin{tabular}{llll}
\hline \multirow{4}{*}{\begin{tabular}{ll}
\multicolumn{2}{l}{$\mathrm{AFB}_{1}$ concentration $(\mathrm{ng} / \mathrm{mL})$} \\
$\left(\mathrm{AFB}_{1}\right.$ reduction $\left.(\%)\right)$
\end{tabular}} \\
\cline { 2 - 4 } & RL mixture & Mono-RL & Di-RL \\
\hline 0 & $3393 \pm 122^{\mathrm{a}}$ & $3393 \pm 122^{\mathrm{a}}$ & $3393 \pm 122^{\mathrm{a}}$ \\
45 & $205 \pm 19^{\mathrm{bC}}$ & $1297 \pm 130^{\mathrm{bcB}}$ & $1850 \pm 268^{\mathrm{bA}}$ \\
& $(93.9 \pm 0.5)$ & $(61.8 \pm 0.4)$ & $(45.5 \pm 7.9)$ \\
90 & $218 \pm 23^{\mathrm{bB}}$ & $1372 \pm 189^{\mathrm{bA}}$ & $1658 \pm 74^{\mathrm{bA}}$ \\
& $(93.6 \pm 0.6)$ & $(59.6 \pm 6.6)$ & $(51.1 \pm 2.2)$ \\
190 & $212 \pm 56^{\mathrm{bC}}$ & $1013 \pm 132^{\mathrm{cdA}}$ & $565 \pm 86^{\mathrm{cB}}$ \\
& $(93.7 \pm 1.6)$ & $(70.1 \pm 3.9)$ & $(83.3 \pm 2.5)$ \\
375 & $74 \pm 21^{\mathrm{bcB}}$ & $816 \pm 160^{\mathrm{deA}}$ & $116 \pm 50^{\mathrm{dB}}$ \\
750 & $(97.8 \pm 0.6)$ & $(75.9 \pm 4.7)$ & $(96.6 \pm 1.4)$ \\
& $43 \pm 18^{\mathrm{cB}}$ & $559 \pm 65^{\mathrm{eA}}$ & $58 \pm 1^{\mathrm{dB}}$ \\
1500 & $(98.7 \pm 0.5)$ & $(83.5 \pm 1.9)$ & $(98.3 \pm 0.0)$ \\
& $16 \pm 1^{\mathrm{cB}}$ & $72 \pm 2^{\mathrm{fA}}$ & $22 \pm 2^{\mathrm{dB}}$ \\
& $(99.5 \pm 0.0)$ & $(97.9 \pm 0.0)$ & $(99.3 \pm 0.0)$ \\
\hline
\end{tabular}

Different lower case letters within the same column and different capital letters within the same row indicate statistically significant differences $(p<0.05)$.

The inhibitory activity of RLs on $\mathrm{AFB}_{1}$ production was similar to those reported for lipopeptide biosurfactants in previous works. The production of $\mathrm{AFB}_{1}$ by $A$. flavus $\mathrm{A} 12$ was reduced by $99.8 \%$ when it was grown in co-culture with two different Bacillus sp. strains due to the production of iturin A and surfactin (Veras et al., 2016). Likewise, when
A. parasiticus NRRL 2999 was grown in co-culture with Bacillus mojavensis $\mathrm{RC1A}$ (which produced surfactin, iturin $\mathrm{A}$ and fengycin), the $\mathrm{AFB}_{1}$ production was reduced by $97.5 \%$ (González Pereyra et al., 2018).

Although Pseudomonas species (different from $P$. aeruginosa) have been reported to inhibit the growth of aflatoxigenic fungi, as well as aflatoxins production, that inhibitory activity has never been related to the production of RLs (Mannaa et al., 2017; Yang et al., 2017).

\subsection{Effect of RLs in the expression of genes involved in sporulation in Aspergillus flavus MUM 17.14}

From the TEM images, it was possible to observe that RLs have a detrimental effect in the hyphal development, including lack and disorganization of the organelles (Fig. 3). This could lead to nutrient deprivation which is the primary signal inducing sporulation in many fungi (Wu et al., 2017). Furthermore, it was also demonstrated that spores production increased 2.8 times in the presence of RLs (Section 3.1). For that reason, the effect of RLs in the expression of regulatory genes involved in the sporulation of $A$. flavus MUM 17.14 was studied. The genes $b r l A, a b a A$ and wetA encode essential transcription factors which constitute the central regulatory pathway that modulates the expression of the genes involved in the different stages of conidiophore development and sporogenesis in A. flavus. BrlA activates the expression of the gene $a b a A$, and AbaA activates the expression of the gene wetA (Wu et al., 2017). It has been reported that a higher expression of the genes $b r l A$ and $a b a A$ is associated with a higher production of spores in A. flavus (Han et al., 2016).

As it can be seen in Fig. 4, at the RLs concentration tested (1500 mg/ L), the genes $b r l A$ and $a b a A$ were down-regulated (2.4-fold and 1.7-fold, 

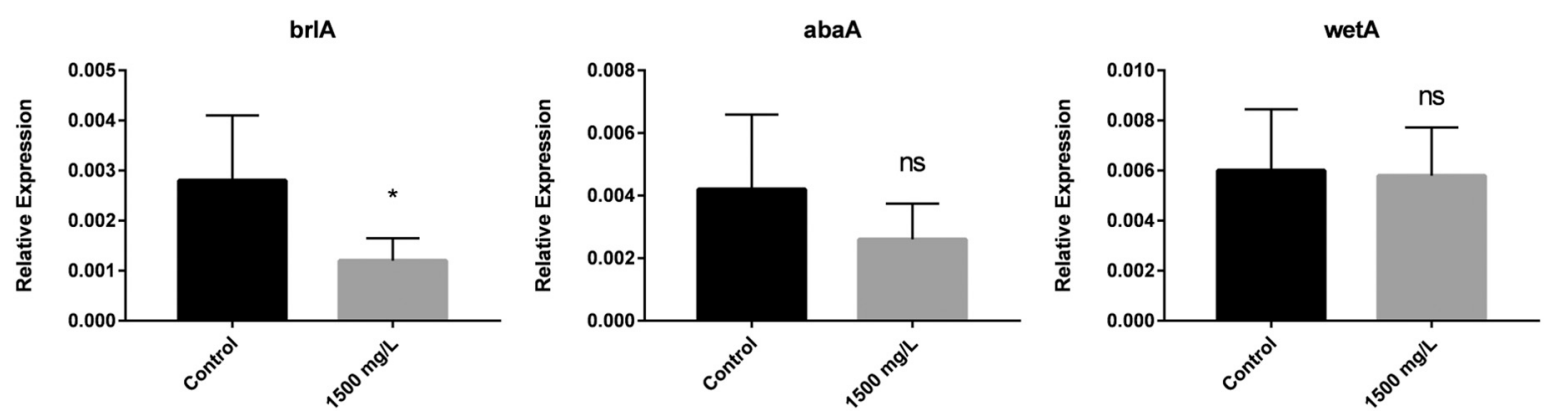

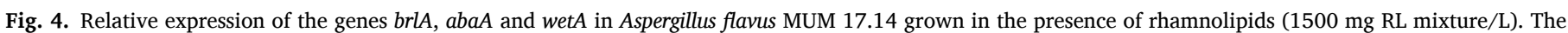

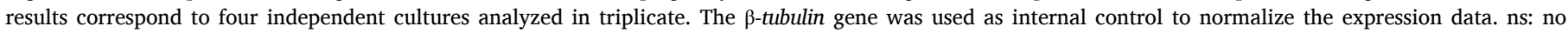
significant differences $(p>0.05)$; * significant differences $(p<0.05)$ (determined by the Student's $t$-test).

respectively), although significant differences $(p<0.05)$ were only observed for the first one. Regarding the gene wetA, its expression was not affected by RLs. Consequently, the higher sporulation observed in the presence of RLs could not be explained by the changes in the expression of the genes studied, suggesting that RLs may have another mechanism of action. Defective expression of the genes $b r l A, a b a A$ and wet $A$ can result in the formation of aberrant conidiophores and spores with defective cell walls (Chang et al., 2012a; Wu et al., 2017), which was not observed in the TEM images of spores exposed to RLs (Fig. 3C) and agrees with the results obtained for the expression of these genes.

\subsection{Effect of RLs in the expression of genes involved in aflatoxins biosynthesis in Aspergillus flavus MUM 17.14}

In the previous sections, it was demonstrated that RLs (RL mixture, mono- and di-RLs) inhibited almost completely the production of aflatoxins in A. flavus MUM 17.14. Accordingly, the effect of RLs in the expression of six genes involved in aflatoxins production was studied: two regulatory genes (aflR and aflS), and four structural genes that participate in different stages of their biosynthesis (aflC, afLE, afLP and aflQ) (Fig. 5). These studies were performed growing A. flavus MUM 17.14 in liquid MEA medium, and it was confirmed that the RL mixture (1500 mg/L) completely inhibited $\mathrm{AFB}_{1}$ production under those conditions.

At least 23 enzymatic reactions and 27 genes clustered in an $80 \mathrm{~Kb}$ operon have been identified in the aflatoxins biosynthetic pathway in
A. flavus and A. parasiticus (Ren et al., 2020). The genes aflR and aflS are the most important regulators of the pathway. AflR and AflS interact to form a transcriptional activation complex that recognizes a consensus sequence in the promoter region of the structural genes from the pathway (Kong et al., 2010; Zhao et al., 2020). Regarding the structural genes studied, the aflC gene encodes a polyketide synthase, involved in the synthesis of the first stable aflatoxin precursor (norsolorinic acid (NOR)). The gene aflE encodes a short-chain aryl alcohol dehydrogenase that participates in the conversion of NOR into averantin (AVN). The $O-$ methyltransferase encoded by the gene aflP catalyzes the conversion of sterigmatocystin (ST) and dihydrosterigmatocystin (DHST) into $O$ methylsterigmatocystin (OMST) and dihydro-O-methylsterigmatocystin (DHOMST), respectively. The P-450 monooxygenase encoded by the gene aflQ participates in the conversion of OMST and DHOMST into $\mathrm{AFB}_{1} / \mathrm{AFG}_{1}$ and $\mathrm{AFB}_{2} / \mathrm{AFG}_{2}$, respectively (Fig. 5) (Chang et al., 2012a; Moon et al., 2018; Wang et al., 2017).

As it can be seen in Fig. 6, the treatment with RLs significantly decreased the expression of the genes aflC (6.4-fold), aflE (44.3-fold), aflP (38.1-fold) and aflQ (2.0-fold), which is in accordance with the complete inhibition of $\mathrm{AFB}_{1}$ production. However, the expression of the regulatory genes studied ( $a f l R$ and $a f l S$ ) was almost unaffected.

A similar relationship between gene expression and aflatoxins production in A. flavus was previously reported. Inhibition of aflatoxins production by different biocontrol agents (e.g. Bacillus megaterium, Eurotium cristatum, Pichia anomala or Streptomyces alboflavus) was associated with a down-regulation of the genes from the aflatoxins

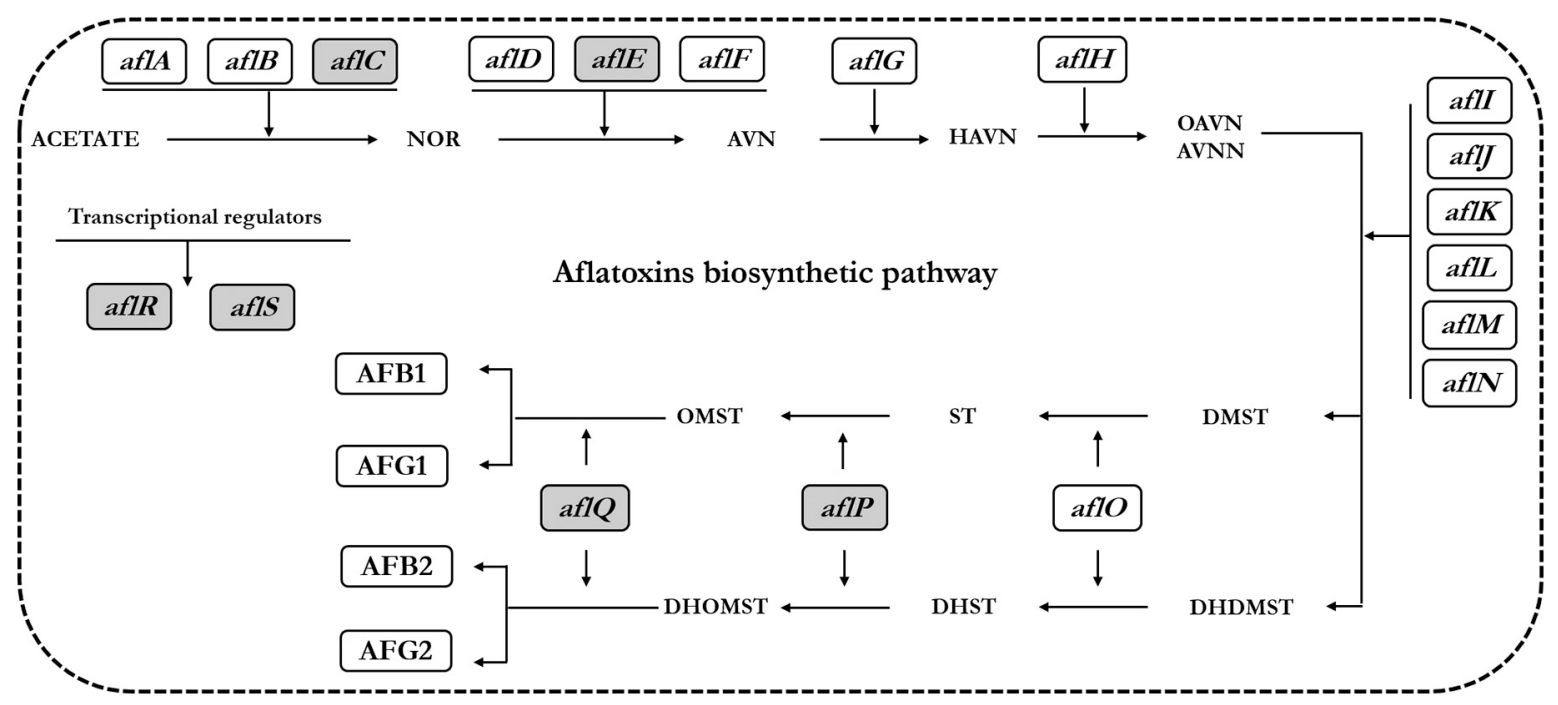

Fig. 5. Schematic representation of the aflatoxins biosynthetic pathway (adapted from Yu et al. (2004)) showing the studied genes. AVN: averantin; AVNN: averufanin; DHDMST: dihydrodemethylsterigmatocystin; DHOMST: dihydro-O-methylsterigmatocystin; DHST: dihydrosterigmatocystin; DMST: demethylsterigmatocystin; HAVN: 5'-hydroxyaverantin; NOR: norsolorinic acid; OAVN: oxoaverantin. OMST: O-methylsterigmatocystin; ST: sterigmatocystin. 
afIR

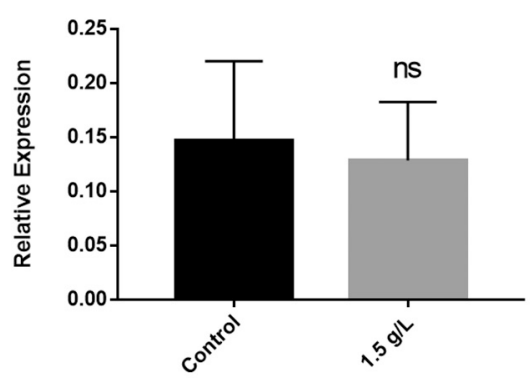

afIE

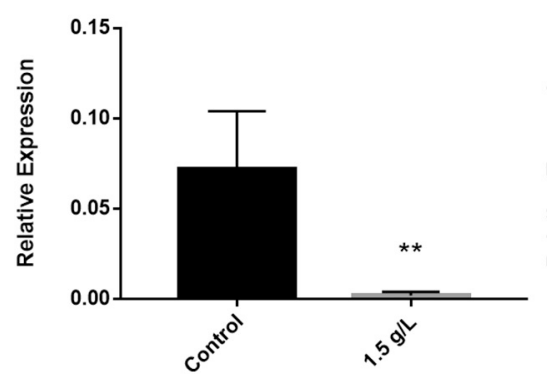

afIS

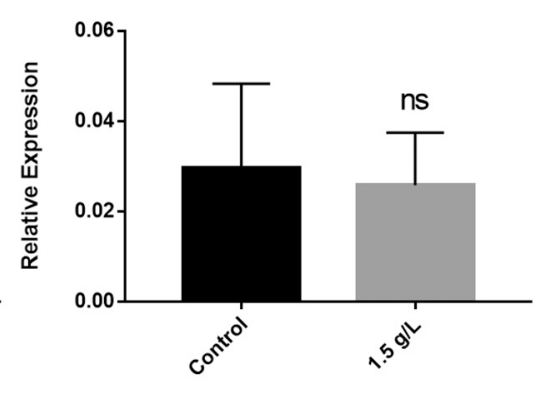

afIP

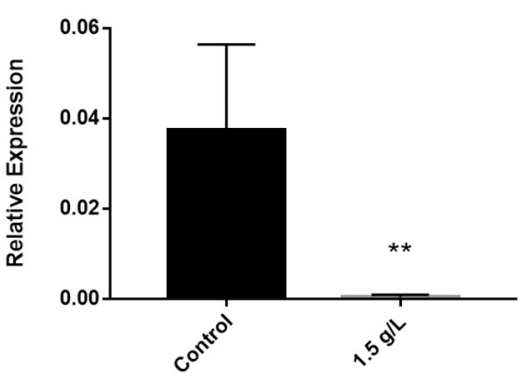

afic

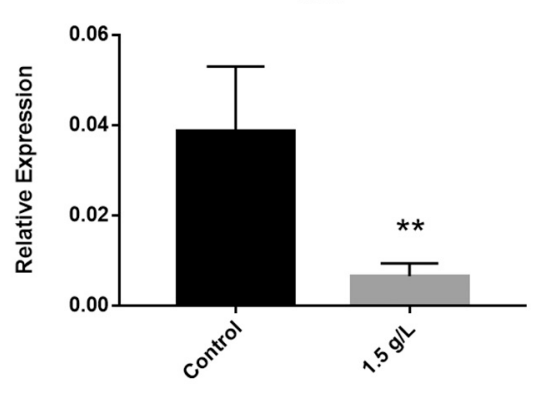

aflQ

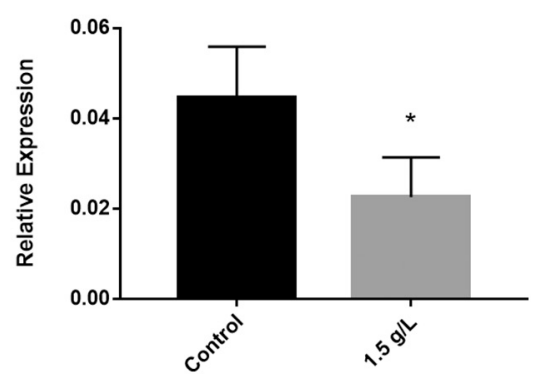

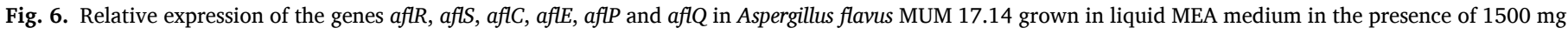

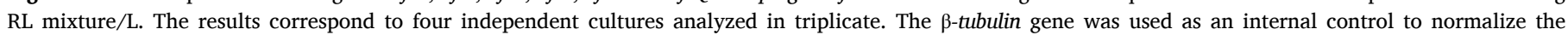

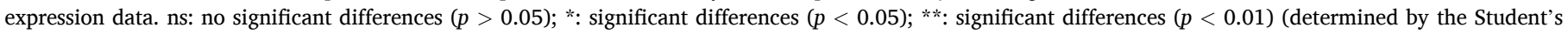
$t$-test).

biosynthetic pathway. In most cases, both structural and regulatory genes were down-regulated (Hua et al., 2014; Kong et al., 2010; Moon et al., 2018; Yang et al., 2019). In other cases, only the expression of one regulatory gene was affected (Zhao et al., 2020). On the contrary, an increase in aflatoxins production was associated with an up-regulation of the gene aflS (Wang et al., 2017). The fact that the expression of some structural genes from the aflatoxins biosynthetic pathway was not correlated to the expression of the regulatory genes aflR and aflS can be due to the existence of a more complex regulatory system, as previously suggested by other researchers. Gallo et al. (2016) studied the effect of temperature and water activity on $\mathrm{AFB}_{1}$ production by $A$. flavus ITEM7828. A direct relationship between $\mathrm{AFB}_{1}$ production and the expression of the structural genes $a f L D$ and $a f l O$ was found. However, the same did not happen with the regulatory genes aflR and aflS, which were highly expressed at conditions that resulted in the production of high and low levels of $\mathrm{AFB}_{1}$ (Gallo et al., 2016). Methyl jasmonate (400 $\left.\mu \mathrm{L} / \mathrm{L}\right)$ inhibited $\mathrm{AFB}_{1}$ production in A. flavus NRRL3357 by $47 \%$ (Li et al., 2021). Under those conditions, 22 of the structural genes from the aflatoxins biosynthetic pathway were significantly downregulated. However, the expression of aflR and aflS was not significantly reduced, thus suggesting that other transcription factors may regulate the expression of the structural genes (Li et al., 2021). Gallic acid ( $8 \mathrm{~g} / \mathrm{L}$ ) completely inhibited $\mathrm{AFB}_{1}$ production in A. flavus NRRL3357 (Zhao et al., 2018). Accordingly, almost all the structural genes from the aflatoxins biosynthetic pathway were significantly downregulated; however, the same was not observed for aflR and aflS. The carbon repression regulator CreA, which can bind directly to the promoter region of at least 14 genes of the aflatoxins biosynthetic pathway, seems to be involved in their regulation, which was further demonstrated by deleting the gene creA in A. flavus NRRL3357 (Zhao et al., 2018).

As natural products synthesized by microorganisms, RLs have been extensively studied for application in cosmetics and pharmaceutics, as well as in agriculture and the food industry, due to their low toxicity and high biodegradability (Hruzová et al., 2020; Robineau et al., 2020; Rodrigues et al., 2017). The applicability of RLs in agriculture, as an alternative to the chemical surfactants, to improve the foliar uptake of herbicides by modifying the wetting leaf surface and enhancing penetration across the cuticular membrane has been demonstrated (Liu et al., 2016). The commercial biofungicide Zonix ${ }^{\mathrm{TM}}$ (NOP Supply LLC., USA), which includes RLs in its formulation, has been approved by the Food and Drug Administration (FDA) to be directly used on vegetables, legumes, and fruit crops to prevent contamination by pathogenic fungi, due to its low mammalian toxicity and non-mutagenicity (Rodrigues et al., 2017). Furthermore, several studies demonstrated that RLs can also stimulate the plant immune system, improving plant protection against fungal and bacterial pathogens (Borah et al., 2015; Crouzet et al., 2021; Robineau et al., 2020). Accordingly, RLs could be used in combination with other fungicides to manage aflatoxins contamination in crops.

\section{Conclusions}

In this work, the inhibitory effect of RLs on the growth and aflatoxins production by A. flavus was reported for the first time. Although growth inhibition did not surpass $50 \%$, aflatoxins production was reduced by $99 \%$. As expected, RLs inhibited the fungal growth by damaging the cell membrane and the cell wall, which caused significant injuries in the hyphal cells. Additionally, they also down-regulated the expression of some genes from the aflatoxins biosynthetic pathway, which almost completely inhibited their production. Therefore, the results gathered in this study suggest that RLs can be considered a promising environmentally-friendly solution that may help in the mitigation of aflatoxins contamination. Nonetheless, more in vitro and field studies are needed to fully understand their anti-aflatoxigenic activity.

\section{CRediT authorship contribution statement}

Ana I. Rodrigues: Conceptualization, Investigation, Writing original draft. Eduardo J. Gudiña: Conceptualization, Investigation, Writing - original draft, Writing - review \& editing. Luis Abrunhosa: Investigation, Writing - review \& editing. Ana R. Malheiro: Investigation. Rui Fernandes: Investigation. José A. Teixeira: 
Conceptualization, Funding acquisition, Supervision, Writing - review \& editing. Lígia R. Rodrigues: Conceptualization, Funding acquisition, Supervision, Writing - review \& editing.

\section{Declaration of competing interest}

The authors declare no conflict of interest.

\section{Acknowledgements}

This study was supported by the Portuguese Foundation for Science and Technology (FCT) under the scope of the strategic funding of UIDB/ 04469/2020 unit and BioTecNorte operation (NORTE-01-0145-FEDER000004) funded by the European Regional Development Fund under the scope of Norte2020 - Programa Operacional Regional do Norte. The authors also acknowledge the support of the i3S Scientific Platform Histology and Electron Microscopy (HEMS), member of the PPBI (PPBIPOCI-01-0145-FEDER-022122). A.I. Rodrigues and L. Abrunhosa acknowledge FCT for the grant SFRH/BD/111600/2015 and the Assistant Research contract CEECIND/00728/2017, respectively.

\section{References}

Afsharmanesh, H., Ahmadzadeh, M., Javan-Nikkhah, M., Behboudi, K., 2014. Improvement in biocontrol activity of Bacillus subtilis UTB1 against Aspergillus flavus using gamma-irradiation. Crop Prot. 60, 83-92. https://doi.org/10.1016/j. cropro.2014.02.013.

Borah, S.N., Goswami, D., Lahkar, J., Sarma, H.K., Khan, M.R., Deka, S., 2015. Rhamnolipid produced by Pseudomonas aeruginosa SS14 causes complete suppression of wilt by Fusarium oxysporum f. sp. pisi in Pisum sativum. BioControl 60, 375-385. https://doi.org/10.1007/s10526-014-9645-0.

Chang, P.K., Scharfenstein, L.L., Ehrlich, K.C., Wei, Q., Bhatnagar, D., Ingber, B.F., 2012a. Effects of laeA deletion on Aspergillus flavus conidial development and hydrophobicity may contribute to loss of aflatoxin production. Fungal Biol. 116 (2), 298-307. https://doi.org/10.1016/j.funbio.2011.12.003.

Chang, P.K., Scharfenstein, L.L., Mack, B., Ehrlich, K.C., 2012b. Deletion of the Aspergillus flavus orthologue of $A$. nidulans flu $G$ reduces conidiation and promotes production of sclerotia but does not abolish aflatoxin biosynthesis. Appl. Environ. Microbiol. 78 (21), 7557-7563. https://doi.org/10.1128/AEM.01241-12.

Crouzet, J., Arguelles-Arias, A., Dhondt-Cordelier, S., Cordelier, S., Prsic, J., Hoff, G., Mazeyrat-Goubeyre, F., Baillieul, F., Clément, C., Onenga, M., Dorey, S., 2021 Biosurfactants in plant protection against diseases: rhamnolipids and lipopeptides case study. Front. Bioeng. Biotechnol. 8, 1014. https://doi.org/10.3389/ fbioe.2020.01014.

Gallo, A., Solfrizzo, M., Epifani, F., Panzarini, G., Perrone, G., 2016. Effect of temperature and water activity on gene expression and aflatoxin biosynthesis in Aspergillus flavus on almond medium. Int. J. Food Microbiol. 217, 162-169. https://doi.org/10.1016/ j.ijfoodmicro.2015.10.026.

Gong, Q., Zhang, C., Lu, F., Zhao, H., Bie, X., Lu, Z., 2014. Identification of bacillomycin $\mathrm{D}$ from Bacillus subtilis fmbJ and its inhibition effects against Aspergillus flavus. Food Control 36, 8-14. https://doi.org/10.1016/j.foodcont.2013.07.034.

González Pereyra, M.L., Martínez, M.P., Petroselli, G., Erra Balsells, R., Cavaglieri, L.R., 2018. Antifungal and aflatoxin-reducing activity of extracellular compounds produced by soil Bacillus strains with potential application in agriculture. Food Control 85, 392-399. https://doi.org/10.1016/j.foodcont.2017.10.020.

Gudiña, E.J., Rodrigues, A.I., de Freitas, V., Azevedo, Z., Teixeira, J.A., Rodrigues, L.R., 2016. Valorization of agro-industrial wastes towards the production of rhamnolipids. Bioresour. Technol. 212, 144-150. https://doi.org/10.1016/j.biortech.2016.04.027.

Guimarães, A., Santiago, A., Teixeira, J.A., Venâncio, A., Abrunhosa, L., 2018. Antiaflatoxigenic effect of organic acids produced by Lactobacillus plantarum. Int. J. Food Microbiol. 264, 31-38. https://doi.org/10.1016/j.ijfoodmicro.2017.10.025.

Han, X., Qiu, M., Wang, B., Yin, W.B., Nie, X., Qin, Q., Ren, S., Yang, K., Zhang, F., Zhuang, Z., Wang, S., 2016. Functional analysis of the nitrogen metabolite repression regulator gene $\mathrm{nmrA}$ in Aspergillus flavus. Front. Microbiol. 7, 1794. https://doi.org/ 10.3389/fmicb.2016.01794.

Hernández-Falcón, T.A., Monter-Arciniega, A., Cruz-Cansino, N.S., Alanís-García, E., Rodríguez-Serrano, G.M., Castañeda-Ovando, A., et al., 2018. Effect of thermoultrasound on aflatoxin $\mathrm{M}_{1}$ levels, physicochemical and microbiological properties of milk during storage. Ultrason. Sonochem. 48, 396-403. https://doi. org/10.1016/j.ultsonch.2018.06.018.

Hruzová, K., Patel, A., Masák, J., Matátková, O., Rova, U., Christakopoulos, P., Matsakas, L., 2020. A novel approach for the production of green biosurfactant from Pseudomonas aeruginosa using renewable forest biomass. Sci. Total Environ. 711, 135099. https://doi.org/10.1016/j.scitotenv.2019.135099.

Hua, S.S.T., Beck, J.J., Sarreal, S.B.L., Gee, W., 2014. The major volatile compound 2phenylethanol from the biocontrol yeast, Pichia anomala, inhibits growth and expression of aflatoxin biosynthetic genes of Aspergillus flavus. Mycotoxin Res. 30, 71-78. https://doi.org/10.1007/s12550-014-0189-z.
Kim, B.S., Lee, J.Y., Hwang, B.K., 2000. In vivo control and in vitro antifungal activity of rhamnolipid B, a glycolipid antibiotic, against Phytophthora capsici and Colletotrichum orbiculare. Pest Manag. Sci. 56, 1029-1035. https://doi.org/10.1002/1526-4998 (200012)56:12<1029::AID-PS238> 3.0.CO;2-Q.

Kong, Q., Shan, S., Liu, Q., Wang, X., Yu, F., 2010. Biocontrol of Aspergillus flavus on peanut kernels by use of a strain of marine Bacillus megaterium. Int. J. Food Microbiol. 139, 31-35. https://doi.org/10.1016/j.ijfoodmicro.2010.01.036.

Lee, H.J., Ryu, D., 2017. Worldwide occurrence of mycotoxins in cereals and cerealderived food products: public health perspectives of their co-occurrence. J. Agric. Food Chem. 65, 7034-7051. https://doi.org/10.1021/acs.jafc.6b04847.

Li, X., Ren, Y., Jing, J., Jiang, Y., Yang, Q., Luo, S., Xing, F., 2021. The inhibitory mechanism of methyl jasmonate on Aspergillus flavus growth and aflatoxin biosynthesis and two novel transcription factors are involved in this action. Food Res. Int. 140, 110051. https://doi.org/10.1016/j.foodres.2020.110051.

Liew, W.P.P., Mohd-Redzwan, S., 2018. Mycotoxin: its impact on gut health and microbiota. Front. Cell. Infect. Microbiol. 8, 60. https://doi.org/10.3389/ fcimb.2018.00060.

Liu, H., Shao, B., Long, X., Yao, Y., Meng, Q., 2016. Foliar penetration enhanced by biosurfactant rhamnolipid. Colloids Surf. B: Biointerfaces 145, 548-554. https://doi. org/10.1016/j.colsurfb.2016.05.058.

Mannaa, M., Oh, J. Y., Kim, K. D., 2017. Biocontrol activity of volatile-producing Bacillus megaterium and Pseudomonas protegens against Aspergillus flavus and aflatoxin production on stored rice grains. Mycobiology 45, 213-219. doi:10.5941/ MYCO.2017.45.3.213.

Marchese, S., Polo, A., Ariano, A., Velotto, S., Costantini, S., Severino, L., 2018. Aflatoxin $\mathrm{B} 1$ and M1: biological properties and their involvement in cancer development. Toxins 10, 214. https://doi.org/10.3390/toxins10060214.

Moon, Y.S., Kim, H.M., Chun, H.S., Lee, S.E., 2018. Organic acids suppress aflatoxin production via lowering expression of aflatoxin biosynthesis-related genes in Aspergillus flavus. Food Control 88, 207-216. https://doi.org/10.1016/j. foodcont.2018.01.017.

Moyne, A.L., Shelby, R., Cleveland, T.E., Tuzun, S., 2001. Bacillomycin D: an iturin with antifungal activity against Aspergillus flavus. J. Appl. Microbiol. 90 (4), 622-629. https://doi.org/10.1046/j.1365-2672.2001.01290.x.

Pfaffl, M.W., 2001. A new mathematical model for relative quantification in real-time RT-PCR. Nucleic Acids Res. 29 (9), 16-21. https://doi.org/10.1093/nar/29.9.e45.

Reddy, K.S., Khan, M.Y., Archana, K., Reddy, M.G., Hameeda, B., 2016. Utilization of mango kernel oil for the rhamnolipid production by Pseudomonas aeruginosa DR1 towards its application as biocontrol agent. Bioresour. Technol. 221, 291-299. https://doi.org/10.1016/j.biortech.2016.09.041.

Ren, X., Zhang, Q., Zhang, W., Mao, J., Li, P., 2020. Control of aflatoxigenic molds by antagonistic microorganisms: inhibitory behaviors, bioactive compounds, related mechanisms, and influencing factors. Toxins 12, 24. https://doi.org/10.3390/ toxins 12010024.

Robineau, M., Le Guenic, S.L., Sanchez, L., Chaveriat, L., Lequart, V., Joly, N., Calonne, M., Jacquard, C., Declerck, S., Martin, P., Dorey, S., Barka, E.A., 2020. Synthetic mono-rhamnolipids display direct antifungal effects and trigger an innate immune response in tomato against Botrytis cinerea. Molecules 25, 3108. https://doi. org/10.3390/molecules25143108.

Rodrigues, A.I., Gudiña, E.J., Teixeira, J.A., Rodrigues, L.R., 2017. Sodium chloride effect on the aggregation behaviour of rhamnolipids and their antifungal activity. Sci. Rep. 7, 12907. https://doi.org/10.1038/s41598-017-13424-x.

Sánchez, M., Aranda, F.J., Espuny, M.J., Marqués, A., Teruel, J., Manresa, A., Ortiz, A., 2007. Aggregation behaviour of a dirhamnolipid biosurfactant secreted by Pseudomonas aeruginosa in aqueous media. J. Colloid Interface Sci. 307, 246-253. https://doi.org/10.1016/j.jcis.2006.11.041.

Sha, R., Jiang, L., Meng, Q., Zhang, G., Song, Z., 2012. Producing cell-free culture broth of rhamnolipids as a cost-effective fungicide against plant pathogens. J. Basic Microbiol. 52 (4), 458-466. https://doi.org/10.1002/jobm.201100295.

Siahmoshteh, F., Hamidi-Esfahani, Z., Spadaro, D., Shams-Ghahfarokhi, M., RazzaghiAbyaneh, M., 2018. Unraveling the mode of antifungal action of Bacillus subtilis and Bacillus amyloliquefaciens as potential biocontrol agents against aflatoxigenic Aspergillus parasiticus. Food Control 89, 300-307. https://doi.org/10.1016/j. foodcont.2017.11.010.

Tleuova, A.B., Wielogorska, E., Talluri, V.S.S.L.P., Stepánek, F., Elliott, C.T., Grigoriev, D. O., 2020. Recent advances and remaining barriers to producing novel formulations of fungicides for safe and sustainable agriculture. J. Control. Release 136, 468-481. https://doi.org/10.1016/j.jconrel.2020.07.035.

Veras, F.F., Paula, A., Correa, F., Welke, J.E., Brandelli, A., 2016. Inhibition of mycotoxin-producing fungi by Bacillus strains isolated from fish intestines. Int. J. Food Microbiol. 238, 23-32. https://doi.org/10.1016/j.ijfoodmicro.2016.08.035.

Wang, B., Han, X., Bai, Y., Lin, Z., Qiu, M., Nie, X., Wang, S., Zhang, F., Zhuang, Z., Yuan, J., Wang, S., 2017. Effects of nitrogen metabolism on growth and aflatoxin biosynthesis in Aspergillus flavus. J. Hazard. Mater. 324, 691-700. https://doi.org/ 10.1016/j.jhazmat.2016.11.043.

Wild, C.P., Gong, Y.Y., 2010. Mycotoxins and human disease: a largely ignored global health issue. Carcinogenesis 31, 71-82. https://doi.org/10.1093/carcin/bgp264.

Wu, M.Y., Mead, M.E., Kim, S.C., Rokas, A., Yu, J.H., 2017. WetA bridges cellular and chemical development in Aspergillus flavus. PLoS One 12 (6), e0179571. https://doi. org/10.1371/journal.pone.0179571.

Yang, X., Zhang, Q., Chen, Z.Y., Liu, H., Li, P., 2017. Investigation of Pseudomonas fluorescens strain 3JW1 on preventing and reducing aflatoxin contaminations in peanuts. PLoSONE 12 (6), e0178810. https://doi.org/10.1371/journal. pone.0178810.

Yang, M., Lu, L., Pang, J., Hu, Y., Guo, Q., Li, Z., Wu, S., Liu, H., Wang, C., 2019. Biocontrol activity of volatile organic compounds from Streptomyces alboflavus TD-1 
against Aspergillus flavus growth and aflatoxin production. J. Microbiol. 57 (5), 396-404. https://doi.org/10.1007/s12275-019-8517-9.

Yu, J., Chang, P., Ehrlich, K.C., Cary, J.W., Bhatnagar, D., Cleveland, T.E., Bennett, J.W., 2004. Clustered pathway genes in aflatoxin biosynthesis. Appl. Environ. Microbiol. 70 (3), 1253-1262. https://doi.org/10.1128/AEM.70.3.1253.
Zhao, X., Zhi, Q.Q., Li, J.Y., Keller, N.P., He, Z.M., 2018. The antioxidant gallic acid inhibits aflatoxin formation in Aspergillus flavus by modulating transcription factors FarB and CreA. Toxins 10, 270. https://doi.org/10.3390/toxins10070270.

Zhao, Q., Qiu, Y., Wang, X., Gu, Y., Zhao, Y., Wang, Y., Yue, T., Yuan, Y., 2020. Inhibitory effects of Eurotium cristatum on growth and aflatoxin B1 biosynthesis in Aspergillus flavus. Front. Microbiol. 11, 921. https://doi.org/10.3389/fmicb.2020.00921. 